\title{
Familial predisposition and susceptibility to the effect of other risk factors for myocardial infarction
}

\author{
Merete Hippe, Jørgen Vestbo, Hans Ole Hein, Knut Borch-Johnsen, Gorm Jensen, \\ Thorkild I A Sørensen
}

The Copenhagen Centre for Prospective Population Studies consists of The Copenhagen County Centre of Preventive Medicine, The Copenhagen Male Study, and The Copenhagen City Heart Study

M Hippe

J Vestbo

T I A Sørensen

Danish Epidemiology Science Centre at the Institute of Preventive Medicine, Copenhagen University Hospital, Copenhagen K, Denmark

M Hippe

T I A Sørensen

The Copenhagen Male Study, Epidemiological Research Unit, Department of Occupational and Environmental Medicine, Copenhagen University Hospital, Copenhagen, Denmark $\mathrm{HO}$ Hein

Copenhagen County Centre of Preventive Medicine, Medical Department C, Glostrup University Hospital, Glostrup, Denmark

K Borch-Johnsen

The Copenhagen City Heart Study, Epidemiological Research Unit, Department of Occupational and Environmental Medicine, Copenhagen University Hospital, Copenhagen, Denmark G Jensen

Correspondence to: Dr M Hippe, Institute of Preventive Medicine, Kommunehospitalet, DK-1399 Copenhagen K, Denmark.

Accepted for publication 6 October 1998

\begin{abstract}
Study objectives-To assess if familial predisposition to myocardial infarction (MI) is an indicator of increased susceptibility to the effect of other established risk factors. The study assessed whether a family history of MI modifies the effect of arterial blood pressure, plasma cholesterol, high and low density lipoprotein cholesterol, \% triglycerides, diabetes mellitus, body mass index, height, smoking habits, alcohol intake, physical activity level, and educational level on the incidence of MI.
\end{abstract}

Design-Prospective population based cohort study of cardiovascular risk and risk factors with follow up of MI by record linkage with the Cause of Death Register and The National Hospital Discharge Register until 1994.

Setting-The Copenhagen Centre for Prospective Population Studies, where data from three Danish studies are integrated. Participants-Subjects were 24664 people aged 20-93, examined between 1976 and 1987.

Main results-A total of 1763 new cases of MI occurred during 293559 person years of observation. All risk factors, including family history of MI reported by 4012 subjects, were, as expected, associated with incidence of MI. With a few inconsistent exceptions we found no significant interactions between family history of $\mathrm{MI}$ and cardiovascular risk factors in their effect on MI.

Conclusions-The familial predisposition to MI does not consistently modify the effect of other risk factors on the risk of MI. However, subjects with a family history of MI may still be regarded as an appropriate target group for screening for cardiovascular risk and intervention against other risk factors.

(F Epidemiol Community Health 1999;53:269-276)

Our knowledge about the risk factors influencing the individual risk of cardiovascular disease is considerable and continuously growing. A family history of myocardial infarction (MI) is a well established risk factor for cardiovascular disease as demonstrated in several types of studies. ${ }^{1-6}$ In a previous study, we showed that subjects with a family history of MI had an adverse cardiovascular risk factor profile with regard to blood pressure, \% cholesterol, ratio between high density lipoprotein cholesterol (HDL cholesterol) and \% cholesterol, and smoking habits, and that these risk factors therefore may be mediators of the familial predisposition to $\mathrm{MI}^{7}$ Many cardiovascular risk factors aggregate within families, suggesting that genetic factors and/or shared environmental factors make significant contributions to the incidence of the disease. ${ }^{8-11}$ Cardiovascular disease is probably a result of interactions between several genetic and environmental factors, ${ }^{8} 12$ but comprehensive analyses of gene-environment interactions are missing. ${ }^{13}$ Familial predisposition includes independent components, the mechanism of which is unknown. This familial predisposition could be attributable to either unknown risk factors or transmissable susceptibility to the effect of known or unknown risk factors. We hypothesise that subjects with a family history of MI may be more susceptible to the adverse effect of cardiovascular risk factors than subjects with no family history of MI.

\section{Methods}

STUDY POPULATION

This study is based on The Copenhagen Centre for Prospective Population Studies in which data from three Danish prospective population studies have been pooled: The Copenhagen City Heart Study (15 786 women and men aged 20-98 years at study entry), ${ }^{14}$ The Glostrup Population Studies from the Copenhagen County Centre of Preventive Medicine, including the DAN-MONICA studies (10 064 women and men aged 30 to 70 at study entry), ${ }^{15}$ and The Copenhagen Male Study (5244 men aged 55 to 75 at study entry). ${ }^{17} \mathrm{~A}$ total of 25291 subjects, from those subpopulations where information on family history of MI was requested at the baseline examination, were included in the present analysis (the question was not posed to the remaining 5803 subjects). Subjects with MI before enrolment in the population studies were excluded ( $n=627)$. Thus 11472 women and 13192 men aged 20-93 years (mean 51.2) at the baseline examinations were included in the analyses.

CARDIOVASCULAR RISK FACTORS

The population studies included assessment of cardiovascular risk factors. Most subjects were drawn as random samples from the background population in the city of Copenhagen and its suburbs, but subjects in The Copenhagen Male 
Study were drawn from major Danish work sites in the Copenhagen area. Response rates varied between 70 and $88 \%$. The studies were approved by the Danish Ethics Committee, and all subjects gave informed consent.

Information on family history of MI, smoking habits, alcohol intake, physical activity level, educational level, and diabetes mellitus was obtained by questionnaire. There were minor differences in the questionnaires between the population studies, which were unimportant with regard to the classification of the subjects in the present study. Systolic and diastolic arterial blood pressure, \% cholesterol, HDL cholesterol, LDL cholesterol, \% triglycerides, height, and weight were measured at the health examinations.

Family history of MI was defined as people reporting $\mathrm{MI}$ in either the mother or the father. The questions were: "Did your mother ever suffer from MI" and "Did your father ever suffer from MI". This definition included subjects with missing information in either the mother or the father if the answer about the other parent was positive. If one of the answers were negative and the other missing, or if both answers were missing, family history of MI was coded as missing.

Smoking habits were studied both as a dichotomous variable; current smoking, yesno, and as an ordinal variable with the following levels: non-smokers; ex-smokers; 1-14 g tobacco/daily; and more than $15 \mathrm{~g}$ tobacco/ daily for women, and 15-24 g tobacco/daily, and more than $25 \mathrm{~g}$ tobacco/daily for men. Ex-smokers were excluded from the interaction analysis because of the heterogeneous composition of this group ( $n=4626$ corresponding to $19 \%$ of the subjects). Inhalation at the time of investigation was included as a dichotomous variable.

Alcohol intake: the subjects were classified according to their total weekly intake of alcohol: less than one beverage a week; $1-6$ beverages per week; 7-13 beverages per week; 14-27 beverages per week; 28-41 beverages per week, and more than 42 beverages per week. One beverage contains 9-13 g alcohol.

Physical activity in leisure time was recorded as three groups; (1) none or very little, (2) moderate physical activity less than four hours per week or light physical activity over a longer period, and (3) moderate physical activity more than four hours per week or competitive sports.

Physical activity at work was recorded as four groups; (1) sitting, (2) standing/walking, (3) walking and lifting, and (4) physically demanding. Unemployed subjects were not included in the analysis of this variable because of the heterogeneous composition of the group ( $n=2045$ corresponding to $8 \%$ of the subjects).

Educational level: the subjects reported years of schooling and were divided into three categories: (1) less than eight years, (2) 8-11 years, and (3) more than 11 years.

Arterial blood pressure was measured after at least five minutes rest. Korotkoff's first and fifth sounds were used as systolic, and diastolic phase 5 blood pressure, respectively.
Blood lipids were non-fasting in the Copenhagen City Heart Studies and fasting in the other population studies. \% Cholesterol, \% triglycerides and HDL cholesterol were analysed by standard methods. LDL cholesterol was determined indirectly according to Friedewald's equation. ${ }^{18}$ Approximately $2 \%$ of the study population had a \% triglyceride level above $4.5 \mathrm{mmol} / 1$, a concentration where the indirect LDL cholesterol determination becomes unreliable. However, excluding subjects with \% triglyceride concentration above 4.5 $\mathrm{mmol} / \mathrm{l}$ did not materially affect the results, and we therefore used the indirectly estimated LDL cholesterol for all subjects.

Arterial blood pressure, \% cholesterol, HDL cholesterol, LDL cholesterol, \% triglycerides, height, and BMI were divided into quartiles or quintiles as appropriate within the population studies of origin, sex, and 10 year age groups. Thus, these risk factors were allowed to vary with age, and possible differences between the population studies were taken into account.

Body mass index was calculated as weight $(\mathrm{kg})$ divided by height squared $\left(\mathrm{m}^{2}\right)$.

FOLLOW UP

Information on fatal and non-fatal MI was obtained from the Cause of Death Register at the National Board of Health and from the National Hospital Discharge Register. International diagnostic criteria for myocardial infarction were used (ICD-8 diagnosis number 410).

Time of observation was recorded as the period from the initial examination until first hospitalisation from MI or death from MI (event), or until death from causes other than MI, disappearance, emigration or survival without MI until 31 December 1993 (censoring). The average follow up time was 12.3 years (range 0-17), and follow up was more than $99 \%$ complete. Less than $1 \%$ were censored because of emigration or disappearance.

\section{STATISTICAL METHODS}

The purpose of the analyses was to elucidate potential interactions between family history of MI and other cardiovascular risk factors in their effect on the incidence of MI. Data were analysed by means of multiple Poisson regression analyses with age as time scale. ${ }^{19}$ All Poisson analyses were stratified by sex, and controlled for population study of origin and age in five year bands.

A lexis expansion of the data set was used to divide the individual follow up period into age bands of five years after the age of 45 and until the age of $90 .{ }^{19}$ The incidence of MI was considered constant in each five year age interval. A person observed in more than one age group contributed with corresponding observation time in both groups.

Analyses of MI incidence in subjects with versus without a family history were performed at different age cut offs: (1) less than 50 years, (2) less than 60 years, and (3) less than 70 years.

A first series of models included age, population study of origin, and one of the risk 
Table 1 Number of subjects with a family history of myocardial infarction (MI), and their relative risk at $95 \%$ confidence intervals of future myocardial infarction

\begin{tabular}{|c|c|c|c|c|}
\hline & \multicolumn{2}{|l|}{ Women } & \multicolumn{2}{|l|}{ Men } \\
\hline & $\begin{array}{l}\text { Family } \\
\text { history of } M I\end{array}$ & $\begin{array}{l}\text { No family } \\
\text { history of } M I\end{array}$ & $\begin{array}{l}\text { Family } \\
\text { history of } M I\end{array}$ & $\begin{array}{l}\text { No family } \\
\text { history of } M I\end{array}$ \\
\hline Number of subjects & 2005 & 6651 & 2007 & 8384 \\
\hline Number of MI cases & 110 & 258 & 217 & 719 \\
\hline Crude relative risk ${ }^{\star}$ & \multicolumn{2}{|c|}{$1.47(1.17,1.85)$} & \multicolumn{2}{|c|}{$1.31(1.13,1.53)$} \\
\hline Adjusted relative riskt & \multicolumn{2}{|c|}{$1.42(1.12,1.79)$} & \multicolumn{2}{|c|}{$1.30(1.11,1.52)$} \\
\hline
\end{tabular}

*Adjusted for age and population study of origin. †Adjusted for age, population study of origin, educational level, current smoking, physical activity in leisure time, systolic blood pressure, $\%$ cholesterol, body mass index, and diabetes.

factors. These results were given in terms of relative risks (RR) and 95\% confidence intervals $(\mathrm{CI})$.

In a second series of models, effects of the risk factors were tested for linearity by means of a log linear Poisson model, where the risk factor was included as an ordinal variable. A $\log$ likelihood ratio test, where the mean in the Poisson distribution was assumed to be proportional with the time of risk, was used to test if the risk factor showed linearity. If linearity is present, this analysis provides a more sensitive assessment of the interaction. These analyses were made separately for subjects with and without a family history of MI (stratified for family history of MI). The log relative risk $(\beta)$ and standard error (SE) of the risk factors are given in a separate table.

In a third series of models, we tested if the $\beta \mathrm{s}$ of the risk factors differed in subjects with and without a family history of MI, using a Wald test. ${ }^{19}$ Interaction was considered significant if the $\beta$ s differed at a 5\% level. As many tests were performed we expected some of them to be significant just by chance. Therefore, we also took into account the level of significance below $5 \%$ and the consistency of the results with previous studies and between the sexes in the interpretations.

In a fourth series of models, all analyses were repeated including relevant confounding variables previously found to have significant influence on the incidence of MI (systolic blood pressure, \% cholesterol, \% triglycerides, diabetes mellitus, BMI, current smoking, weekly alcohol intake, physical activity level, and educational level). In the models analysing the interaction between effect of family history of MI and effect of each of the risk factors on incidence of MI, all the abovementioned risk factors were included as confounding variables.

As part of our analysis, we tested the robustness of the results at different definitions of the variable "family history of MI" by including the missing values in different ways: (1) by excluding all subjects with missing values (the most restrictive definition), and (2) by including all missing values as "not having family history of MI".

The statistical analyses were made on a PC using the statistical package Stata, version 5.0.

\section{Results}

Among the 24664 participants, 378 fatal and 1385 non-fatal events occurred during 293559 person years of observation. Mean age of those who developed MI was 66 years. A total of 19047 subjects (78\%) of those to whom the questions were posed, did answer the question on family history of MI. A total of 4012 subjects reported a family history of MI, corresponding to $21 \%$ of the responding participants (table 1).

In both sexes, the number of subjects with missing values was less than $3 \%$ for most risk factors. However, in the Copenhagen City Heart Study, HDL cholesterol was not measured at the first examination in 1977, and triglycerides were not measured at the second examination in 1982. The number of subjects included in the analyses of HDL and LDL cholesterol therefore, was only $49 \%$, and only $92 \%$ were included in the analyses of $\%$ triglycerides.

\section{RISK FACTOR DISTRIBUTION BY FAMILY HISTORY} OF MI

As previously reported, ${ }^{7}$ there was a tendency to higher blood pressure, \% cholesterol, LDL cholesterol, \% triglyceride, and BMI, and towards lower HDL cholesterol in subjects with a family history of MI as compared with subjects without such a history. In both men and women, subjects not answering the question on family history of MI had a lower education and were less likely to be in the highest HDL quartile. Among men, the percentage of smokers and inhalers was slightly higher in subjects not answering the question than in subjects answering the questions while female non-responders tended to be minimum users of alcohol.

RISK FACTORS AND INCIDENCE OF MI

The RR of MI in subjects with a family history of MI compared with no family history of MI was $1.47(1.17-1.85)$ in women, and 1.31 $(1.12-1.53)$ in men (table 1$)$. In both sexes, the $\mathrm{RR}$ of MI in subjects with versus without a family history of MI decreased with increasing age of subjects (table 2).

Family history of MI, arterial blood pressure, \% cholesterol, LDL cholesterol, \% triglycerides, BMI, diabetes mellitus, smoking habits, and inhalation were, as expected, strongly and positively associated with incidence of MI in a monotonous, independent, and consistent way. HDL cholesterol, height, alcohol intake, physical activity level in leisure time and educational level were all inversely associated with incidence of MI. Physical activity at work was not associated with incidence of MI in this population. The age and population study adjusted RRs and $95 \% \mathrm{CI}$ for the risk factors are shown in table 3. In both women and men, and in subjects both with and without a family history

Table 2 Relative risks and 95\% confidence intervals of myocardial infarction at different age cut offs. Men and women with versus without familial predisposition to $M I$

\begin{tabular}{llll}
\hline $\begin{array}{l}\text { Age }(y) \text { at } \\
\text { observation/ } \\
\text { follow up }\end{array}$ & Women & & Men \\
\cline { 2 - 2 } & Relative risk & & Relative risk \\
\hline$<50$ & $2.26(0.88,5.78)$ & & $3.08(1.81,5.24)$ \\
$<60$ & $1.21(0.74,1.97)$ & & $1.59(1.21,2.10)$ \\
$<70$ & $1.50(1.13,1.99)$ & & $1.36(1.14,1.63)$ \\
\hline
\end{tabular}

^Adjusted for age and population study of origin. 
Table 3 Relative risks at 95\% confidence intervals (CI) of myocardial infarction by different risk factors

\begin{tabular}{|c|c|c|}
\hline \multirow[b]{2}{*}{ Risk factor } & \multirow{2}{*}{$\begin{array}{l}\begin{array}{l}\text { Women } \\
(n=11472)\end{array} \\
\begin{array}{l}\text { Relative risks* } \\
(95 \% \text { CI })\end{array}\end{array}$} & \multirow{2}{*}{$\begin{array}{l}\begin{array}{l}\text { Men } \\
(n=13 \text { 192) }\end{array} \\
\begin{array}{l}\text { Relative risks* } \\
(95 \% \text { CI })\end{array}\end{array}$} \\
\hline & & \\
\hline \multicolumn{3}{|l|}{ Systolic blood pressure $†$} \\
\hline$<25 \%$ & 1.00 & 1.00 \\
\hline $25-50 \%$ & $1.22(0.93,1.59)$ & $1.28(1.08,1.52)$ \\
\hline $50-75 \%$ & $1.23(0.94,1.61)$ & $1.38(1.17,1.64)$ \\
\hline$>75 \%$ & $1.73(1.35,2.23)$ & $1.91(1.63,2.25)$ \\
\hline \multicolumn{3}{|c|}{ Diastolic blood pressure } \\
\hline$<20 \%$ & 1.00 & 1.00 \\
\hline $20-40 \%$ & $1.02(0.75,1.39)$ & $1.02(0.84,1.23)$ \\
\hline $40-60 \%$ & $1.14(0.84,1.53)$ & $1.28(1.06,1.54)$ \\
\hline $60-80 \%$ & $1.40(1.05,1.86)$ & $1.27(1.06,1.54)$ \\
\hline$>80 \%$ & $1.64(1.24,2.17)$ & $1.76(1.47,2.09)$ \\
\hline \multicolumn{3}{|l|}{$\mathrm{P}$ cholesterol $\dagger$} \\
\hline$<20 \%$ & 1.00 & 1.00 \\
\hline $20-40 \%$ & $1.09(0.80,1.49)$ & $1.14(0.92,1.40)$ \\
\hline $40-60 \%$ & $0.95(0.69,1.31)$ & $1.45(1.19,1.76)$ \\
\hline $60-80 \%$ & $1.15(0.85,1.56)$ & $1.67(1.38,2.03)$ \\
\hline$>80 \%$ & $2.09(1.60,2.75)$ & $2.11(1.75,2.54)$ \\
\hline \multicolumn{3}{|l|}{ HDL cholesterol $\dagger$} \\
\hline$<25 \%$ & 1.00 & 1.00 \\
\hline $25-50 \%$ & $0.77(0.48,1.22)$ & $0.68(0.54,0.86)$ \\
\hline $50-75 \%$ & $0.39(0.22,0.69)$ & $0.51(0.40,0.66)$ \\
\hline$>75 \%$ & $0.21(0.11,0.41)$ & $0.37(0.28,0.49)$ \\
\hline \multicolumn{3}{|l|}{ LDL cholesterol $\dagger$} \\
\hline$<25 \%$ & 1.00 & 1.00 \\
\hline $25-50 \%$ & $0.73(0.34,1.59)$ & $1.12(0.81,1.54)$ \\
\hline $50-75 \%$ & $1.23(0.62,2.44)$ & $1.63(1.21,2.19)$ \\
\hline$>75 \%$ & $2.08(1.12,3.86)$ & $1.98(1.49,2.63)$ \\
\hline $\mathrm{P}$ triglycerides $\dagger$ & & \\
\hline$>25 \%$ & 1.00 & 1.00 \\
\hline $25-50 \%$ & $1.19(0.89,1.60)$ & $1.22(1.02,1.47)$ \\
\hline $50-75 \%$ & $1.49(1.12,1.97)$ & $1.51(1.27,1,80)$ \\
\hline$>75 \%$ & $2.42(1.86,3.14)$ & $1.93(1.64,2.28)$ \\
\hline Diabetes mellitus & & \\
\hline No & 1.00 & 1.00 \\
\hline Yes & $5.14(3.57,7.40)$ & $2.26(1.72,2.87)$ \\
\hline Height $†$ & & \\
\hline$<25 \%$ & 1.00 & 1.00 \\
\hline $25-50 \%$ & $1.02(0.81,1.29)$ & $0.97(0.83,1.14)$ \\
\hline $50-75 \%$ & $0.90(0.71,1.44)$ & $0.85(0.73,0.99)$ \\
\hline$>75 \%$ & $0.75(0.58,0.96)$ & $0.81(0.69,0.95)$ \\
\hline $\mathrm{BMI}+$ & & \\
\hline$<25 \%$ & 1.00 & 1.00 \\
\hline $25-50 \%$ & $0.83(0.64,1.07)$ & $1.15(0.97,1.40)$ \\
\hline $50-75 \%$ & $0.97(0.75,1.25)$ & $1.34(1.14,1.58)$ \\
\hline$>75 \%$ & $1.33(1.05,1.69)$ & $1.61(1.37,1.90)$ \\
\hline Current smoking & & \\
\hline No & 1.00 & 1.00 \\
\hline Yes & $2.17(1.80,2.63)$ & $1.42(1.25,1.61)$ \\
\hline $\begin{array}{l}\text { Smoking habits } \\
\text { (g tobacco/daily) }\end{array}$ & & \\
\hline Never & 1.00 & 1.00 \\
\hline Ex-smoker & $0.99(0.71,1.38)$ & $1.17(0.92,1.48)$ \\
\hline $1-14$ & $2.02(1.59,2.56)$ & $1.47(1.16,1.86)$ \\
\hline $15-24$ & $2.51(1.96,3.22)$ & $1.67(1.33,2.09)$ \\
\hline$\geqslant 25$ & - & $1.74(1.35,2.24)$ \\
\hline Inhalation & & \\
\hline No & 1.00 & 1.00 \\
\hline Yes & $2.17(1.80,2.61)$ & $1.46(1.30,1.64)$ \\
\hline Alcohol intake & & \\
\hline (beverages a week) & & \\
\hline$<1$ & 1.00 & 1.00 \\
\hline $1-6$ & $0.74(0.61,0.90)$ & $0.74(0.61,0.89)$ \\
\hline $7-13$ & $0.75(0.57,1.00)$ & $0.65(0.55,0.78)$ \\
\hline $14-27$ & $0.75(0.53,1.08)$ & $0.62(0.52,0.75)$ \\
\hline$\geqslant 28-41$ & - & $0.58(0.47,0.71)$ \\
\hline $\begin{array}{l}\text { Physical activity in leisur } \\
\text { (hours per week) }\end{array}$ & e time & \\
\hline None & 1.00 & 1.00 \\
\hline$<4$ & $0.76(0.62,0.93)$ & $0.84(0.73,0.97)$ \\
\hline$\geqslant 4$ & $0.65(0.50,0.85)$ & $0.69(0.59,0.81)$ \\
\hline Physical activity at work & & \\
\hline Sitting & 1.00 & 1.00 \\
\hline Standing/walking & $1.03(0.80,1.32)$ & $1.04(0.88,1.23)$ \\
\hline Walking/liftting & $1.03(0.75,1.41)$ & $1.04(0.87,1.24)$ \\
\hline Physically demanding & - & $1.03(0.81,1.30)$ \\
\hline $\begin{array}{l}\text { Educational level } \\
\text { (years) }\end{array}$ & & \\
\hline$<8$ & 1.00 & 1.00 \\
\hline $8-11$ & $0.67(0.55,0.80)$ & $0.83(0.73,0.93)$ \\
\hline$\geqslant 11$ & $0.49(0.31,0.77)$ & $0.61(0.49,0.75)$ \\
\hline
\end{tabular}

*Adjusted for age and population study of origin. The lowest group was used as reference group. +Quartiles or quintiles estimated within population study of origin, sex and 10 year age group.
KEY POINTS

- Parental history of myocardial infarction (MI) is a risk factor for future MI only partly explained by other known risk factors.

- Hence, familial predisposition includes independent components, the mechanism of which is unknown.

- This familial predisposition could be attributable to either unknown risk factors or transmissable susceptibility to the effect of known or unknown risk factors.

- A family history of MI proved not to convey greater susceptibility to the adverse effect of known cardiovascular risk factors.

- Subjects with a family history of MI may still be considered an appropriate high risk target group for preventive intervention.

of MI, none of the risk factors departed from a linear trend. The log relative risks $(\beta)$ stratified by family history are given in table 4 .

INTERACTIONS BETWEEN FAMILY HISTORY OF MI AND OTHER RISK FACTORS ON INCIDENCE OF MI Table 4 shows the statistical assessment of the interaction between family history of MI and the risk factors on the incidence of MI. We found no significant interactions on the incidence of MI between family history of MI and most of the investigated risk factors.

In men, we found a significant interaction $(p<0.001)$ between family history of MI and HDL cholesterol on the incidence of MI. Here, the decreasing incidence of MI with increasing HDL cholesterol values was apparent only in subjects who had no family history of MI. In women, there was a strong negative association between HDL cholesterol and incidence of MI, irrespective of family history, and no statistically significant interaction was observed (fig 1).

We found a significant interaction $(\mathrm{p}<0.05$ in women and 0.02 in men) between family history of MI and inhalation, but the results were in opposite directions in women and men. In women, a family history of MI reinforced the effect of inhaling on incidence of MI, whereas in men a family history of MI dampened the effect.

In women, we found a significant interaction $(\mathrm{p}<0.01)$ between family history of MI and alcohol intake, whereas no such interaction was found in men; the decreasing incidence of MI with increasing alcohol intake was only present in women without a family history of MI.

In summary, we found no interaction between family history of MI and most risk factors in their effect on the incidence of MI, and where we found interactions, the results were inconsistent in women and men.

CONFOUNDER AND ROBUSTNESS ANALYSIS

The influence on the hypotheses tested of the age of MI in the probands was analysed. None of the interaction analyses, as presented in table 4 , were significantly influenced by 
Table 4 Log relative risks and standard error (SE) for myocardial infarction (MI) in subjects with and without a family history of MI

\begin{tabular}{|c|c|c|c|c|c|c|c|c|}
\hline & \multicolumn{4}{|l|}{ Women } & \multicolumn{4}{|l|}{ Men } \\
\hline & \multicolumn{2}{|c|}{ Family history of $M I(n=2005)$} & \multicolumn{2}{|c|}{ No family history $(n=6651)$} & \multicolumn{2}{|c|}{ Family history of $M I(n=2007)$} & \multicolumn{2}{|c|}{ No family history $(n=8384)$} \\
\hline & $\beta(S E)$ crude $e^{\star}$ & $\beta(S E)$ adjusted & $\beta(S E)$ crude $e^{\star}$ & $\beta(S E)$ adjusted & $\beta(S E)$ crude $^{\star}$ & $\beta(S E)$ adjusted & $\beta(S E)$ crude $e^{\star}$ & $\beta(S E)$ adjusted \\
\hline Systolic blood pressure & $0.12(0.09)$ & $0.12(0.09)+$ & $0.16(0.06)$ & $0.16(0.06)+$ & $0.17(0.06)$ & $0.15(0.06)+$ & $0.20(0.03)$ & $0.19(0.04)+$ \\
\hline Diastolic blood pressure & $0.14(0.06)$ & $0.14(0.07) \dagger$ & $0.18(0.05)$ & $0.18(0.05) \dagger$ & $0.12(0.05) \dagger$ & $0.10(0.05)$ & $0.13(0.03)$ & $0.14(0.03) \dagger$ \\
\hline P cholesterol & $0.26(0.07)$ & $0.26(0.07) \ddagger$ & $0.11(0.04)$ & $0.10(0.04) \ddagger$ & $0.16(0.05)$ & $0.15(0.05) \ddagger$ & $0.17(0.03)$ & $0.16(0.03) \ddagger$ \\
\hline HDL cholesterol & $-0.69(0.24)$ & $-0.69(0.24) \ddagger$ & $-0.70(0.15)$ & $-0.66(0.15) \ddagger$ & $-0.08(0.10)$ & $-0.08(0.10) \ddagger$ & $-0.46(0.06)$ & $-0.44(0.06) \ddagger$ \\
\hline LDL cholesterol & $0.22(0.22)$ & $0.22(0.22) \ddagger$ & $0.29(0.13)$ & $0.27(0.14) \ddagger$ & $0.21(0.10)$ & $0.21(0.10) \ddagger$ & $0.23(0.05)$ & $0.21(0.05) \ddagger$ \\
\hline $\mathrm{P}$ triglycerides & $0.32(0.09)$ & $0.33(0.09) \ddagger$ & $0.30(0.06)$ & $0.28(0.06) \ddagger$ & $0.15(0.06)$ & $0.10(0.06) \ddagger$ & $0.24(0.03)$ & $0.22(0.04) \ddagger$ \\
\hline Diabetes mellitus & $1.02(0.59)$ & $1.02(0.59) \ddagger$ & $1.80(0.24)$ & $1.76(0.25) \ddagger$ & $1.18(0.28)$ & $1.24(0.28) \ddagger$ & $0.68(0.19)$ & $0.66(0.19) \ddagger$ \\
\hline Height & $-0.21(0.09)$ & $-0.18(0.09) \Phi$ & $-0.07(0.05)$ & $-0.05(0.05) \sqrt{S}$ & $-0.16(0.06)$ & $-0.11(0.06) \S$ & $-0.07(0.03)$ & $-0.04(0.03) \S$ \\
\hline Body Mass Index & $0.04(0.09)$ & $0.07(0.09) \uparrow$ & $0.16(0.06)$ & $0.19(0.06)$ & $0.19(0.06)$ & $0.20(0.06)$ & $0.13(0.03)$ & $0.16(0.03)$ \\
\hline Current smoking & $0.99(0.22)$ & $1.01(0.22) \ddagger$ & $0.81(0.14)$ & $0.84(0.22) \ddagger$ & $0.17(0.15)$ & $0.19(0.15) \ddagger$ & $0.48(0.08)$ & $0.52(0.09) \ddagger$ \\
\hline Alcohol intake & $0.10(0.10)$ & $0.08(0.10)$ & $-0.27(0.07)$ & $-0.30(0.07)$ & $-0.13(0.05)$ & $-0.14(0.06)$ & $-0.16(0.03)$ & $-0.17(0.03)$ \\
\hline Physical activity in leisure time & $-0.07(0.15)$ & $-0.07(0.15) \ddagger$ & $-0.36(0.10)$ & $-0.34(0.10) \ddagger$ & $-0.16(0.10)$ & $-0.15(0.10) \ddagger$ & $-0.22(0.05)$ & $-0.21(0.05) \ddagger$ \\
\hline Educational level & $-0.47(0.17)$ & $-0.49(0.17)^{\mathrm{a}}$ & $-0.33(0.11)$ & $-0.30(0.11)^{\mathrm{a}}$ & $-0.37(0.10)$ & $-0.36(0.10)^{\mathrm{a}}$ & $-0.19(0.06)$ & $-0.17(0.06)^{\mathrm{a}}$ \\
\hline
\end{tabular}

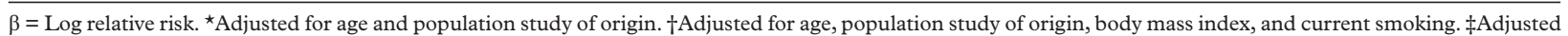
for age, population study of origin, and body mass index. §Adjusted for age, population study of origin, and educational level. $\uparrow$ Adjusted for age, population study of origin, and current smoking. ${ }^{a}$ Adjusted for age, population study of origin, current smoking, and weekly alcohol intake.

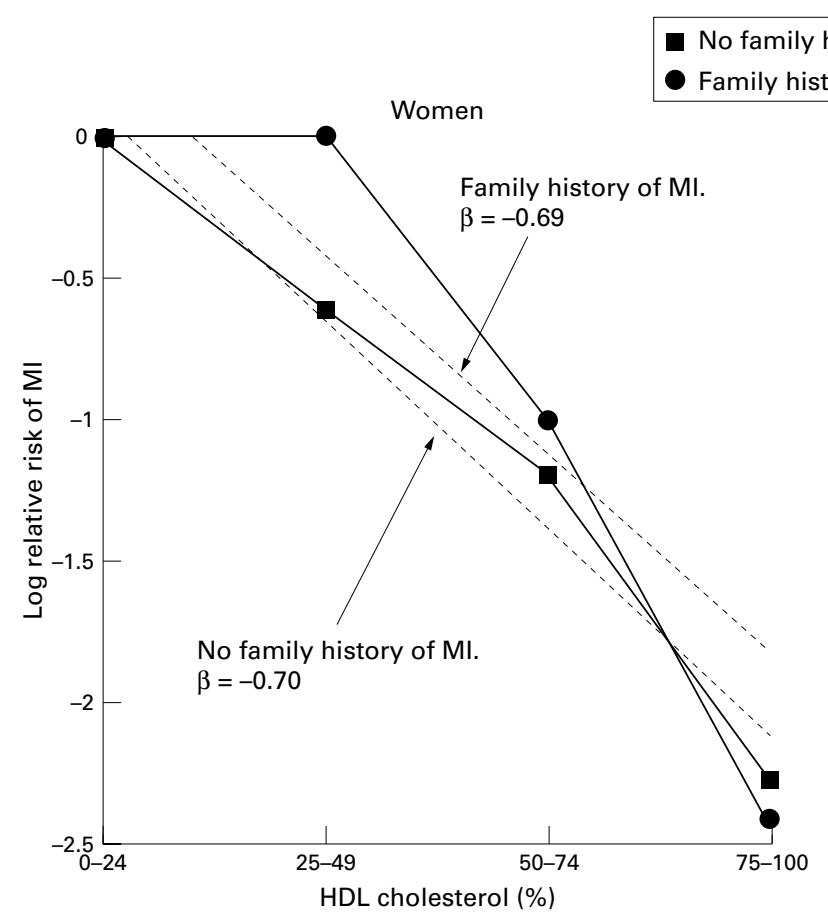

No family history of MI
Family history of MI

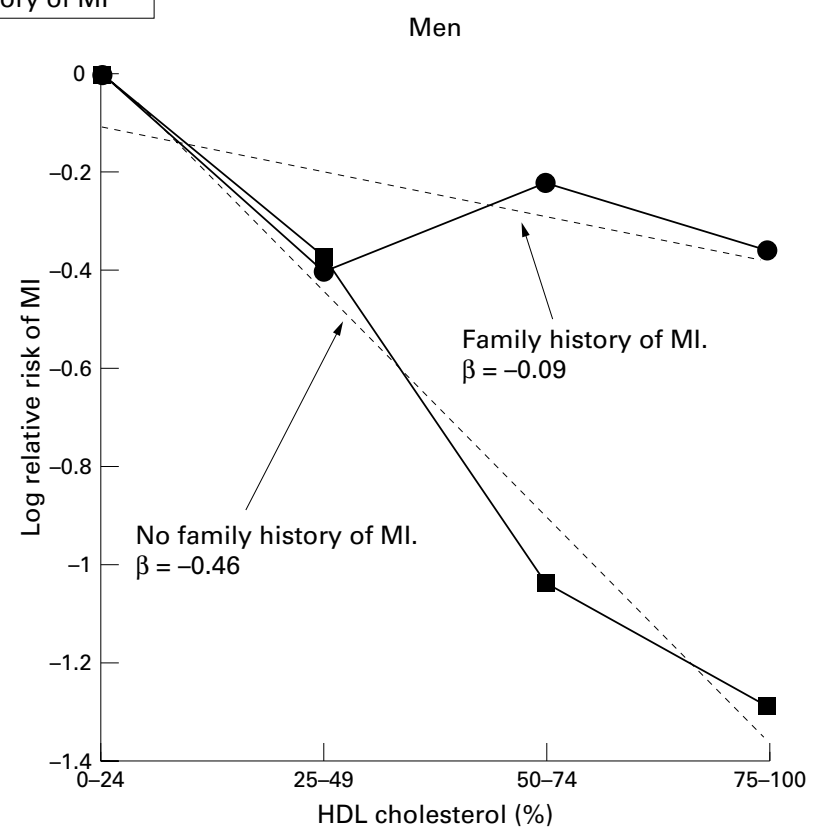

Figure 1 The interaction between family history of myocardial infarction (MI) and HDL cholesterol. The log relative risk ( $\beta$ ) of future MI by family history of MI and increasing HDL cholesterol (in quartiles). In men, there is a significant interaction between family history of MI and HDL cholesterol $(p<0.001)$ indicating that the decreasing risk of MI with increasing HDL cholesterol may be apparent only in men without a family history of MI. In women no interaction was observed.

age as presented in table 2. Inclusion of relevant confounding variables slightly changed the $\beta$ s but did not affect any of the main results (table 4 ).

The use of different definitions of family history of MI did not change any of the results significantly (including the results of interaction analysis). When subjects with missing values were excluded, the RR and $95 \%$ CI of $\mathrm{MI}$ in subjects with a family history of MI compared with subjects without such a history, was $1.41(1.1,1.81)$ in women; and $1.26(1.07$, $1.49)$ in men. Including all missing values as "not having a family history of MI" did not change the relative risk of MI significantly (RR and 95\% CI: $1.40(1.13,1.73)$ in women, and $1.29(1.12,1.50)$ in men).

Furthermore, the relative risk of $\mathrm{MI}$ in subjects not answering the question on family history of MI did not differ significantly from subjects without a family history of MI (RR and $95 \% \mathrm{CI}$ : women 1.16 (0.95, 1.43); men $1.06(0.92,1.21))$.

To exclude that a healthy worker effect has influenced the results in the Copenhagen Male Study, all analyses were repeated excluding this subpopulation. None of the results were affected.

\section{Discussion}

The main new finding of this large prospective study of almost 25000 people, was that familial predisposition to MI does not consistently change the effects of most established cardiovascular risk factors on risk of MI.

As in most other studies, arterial blood pressure, \% cholesterol, HDL cholesterol, LDL cholesterol, \% triglycerides, smoking 
habits, diabetes mellitus, alcohol intake, physical activity in leisure time, height, BMI, and educational level were clear risk factors for MI. ${ }^{20-26}$ There was a simple dose response relation between each of these risk factors and risk of future MI of the same strength in subjects with and without a family history of MI.

INTERACTION ANALYSIS

A family history of MI is a well established risk factor for MI. ${ }^{1-5}{ }^{27}$ All the risk factors dealt with in this article tend to aggregate within families because of shared genetic and/or environmental influences. ${ }^{28}$ This study investigates the possible synergism or antagonism between these influences. Few studies of risk of MI have, however, investigated interactions between cardiovascular risk factors and family history of $\mathrm{MI}$, probably because it requires long follow up time and a relatively large number of cases.

In agreement with the results in this study, other studies have reported no interaction between family history of MI and systolic blood pressure level, and between family history of MI and \% cholesterol level. ${ }^{127}{ }^{29-31}$ In a study by Khaw et al, the risk of cardiovascular death in men with high systolic blood pressure or high \% cholesterol was significantly higher in men without a family history of MI than in men with a family history of $\mathrm{MI} .^{31}$ A similar trend, although not statistically significant, was found in women by Khaw et al, and still no significant interactions were found in either men or women. ${ }^{31}$

The decreasing incidence of MI with increasing HDL cholesterol was apparent in women, irrespective of family history, but only in men who had no family history of MI. Two cross sectional studies have investigated possible interactions between family history of $\mathrm{MI}$ and HDL cholesterol in MI cases. ${ }^{24}{ }^{32}$ In the study by Rossouw et al, there was no interaction between family history and HDL cholesterol in either women or men. Simons et al found a different interaction between a family history of MI and HDL cholesterol in subjects with MI (case-control study). They found the opposite effect, namely that HDL cholesterol was a significant predictor of MI only in subjects with a family history of $\mathrm{MI}^{24}$ The findings regarding this interaction have been few and conflicting, and should be explored further in other large prospective studies.

The lack of interaction between family history of MI and obesity, and between family history of MI and diabetes mellitus found in our study, is in accordance with other results. ${ }^{12931}$ We are not aware of other reports assessing interaction between family history of MI and LDL cholesterol, between family history of MI and height, and between family history of $\mathrm{MI}$ and \% triglycerides.

In agreement with our study, other investigators have found no interaction between family history of $\mathrm{MI}$ and current smoking. ${ }^{127}$ Moreover, we also did not find any interaction between family history of MI and other aspects of smoking habits (except for inhalation, see below). Two case-control studies have reported interaction between current smoking and fam- ily history of coronary heart disease. ${ }^{29} 33$ However, in both studies, interactions were compatible with a multiplicative effect rather than a modifying effect of family history of MI. In a prospective study by Khaw et al, the RR of cardiovascular death was 2.3 times higher in smoking subjects with a family history of MI compared with smoking subjects without a family history, and the RR of a family history of $\mathrm{MI}$ on cardiovascular death differed in smoking and non-smoking subjects. This indicates interaction between family history of MI and current smoking. ${ }^{31}$ Their study was based on a smaller study population and a shorter time of follow up than ours. Still, the difference between the results in our study and the study by Khaw et al is unclear, but it is unlikely to be caused by differences between percentage of smokers or differences in the severity of the outcome.

In this study, we found an interaction between family history of $\mathrm{MI}$ and inhalation in both women and men. In women, family history of MI reinforced the effect of inhaling, whereas, in men, a family history of MI dampened the effect of inhaling. To our knowledge, this is the first study to investigate such interaction, and to exclude that these inconsistent results are chance findings they have to be assessed in other studies.

In men, we did not find any interaction between family history of MI and alcohol intake on incidence of MI, whereas in women, we found a negative interaction. This indicates that the beneficial effect of alcohol intake in women may be less in subjects with a family history of MI compared with subjects with no family history. Fuchs et $a l^{34}$ investigated all cause mortality at different levels of alcohol consumption in women who had one or more cardiovascular risk factors, including $\mathrm{MI}$ in a parent less than 60 years of age. They found that the benefit associated with light to moderate alcohol intake was most apparent among women with risk factors for coronary heart disease, but no significant interaction between mortality associated with alcohol intake and coronary risk factor status. Even though the results seem to differ, it is difficult to compare our study with the study by Fuchs et al.

\section{LIMITATIONS}

This study has certain limitations that have to be considered in the interpretation. These can be divided into limitations related to the risk factors and limitations related to the outcome.

\section{Limitations related to the risk factors}

Information on some of the risk factors was based on self reports. The implicit measurement inaccuracy may diminish the associations. ${ }^{35}$ However, in this and several other populations, all self reported risk factors, including family history of MI, were strong and significant predictors of future $\mathrm{MI}^{3}{ }^{3212327} 36$ which suggest that there are no major random misclassification. Studies of self reported family history have shown different validity. ${ }^{37-39}$ In a study by Greenlund et al, parental cardiovascular disease could not be verified in $14 \%$ of 
cases by interviewing parents or next of kin. De Backer et al found that more than half of the university students who reported occurrence of MI in parents less than 55 years, proved to be unreliable, whereas Kee et al found self reported family history of MI to be almost as predictive of the estimated incidence of $\mathrm{MI}$ as the validated family history of MI, and the accuracy of self reported family history was almost equal in MI cases and controls. ${ }^{39}$ The kind of data that we have had available are likely to be similar to those that can be obtained in routine surveys and clinical practice.

Ideally, the analyses should take into account the age specific incidence of MI in both the subjects and their parents. In our study, we assumed that younger subjects, on average, have younger parents. We found that the importance of a family history decreased with age, suggesting that the familial component (genetic or shared environment, or both) may be more strongly expressed in early MI. However, although non-familial environmental factors have more time to operate by advancing age, familial factors may also be involved in MI occurring at an older age. Repeating the interaction analysis including only younger subjects did not change any of the results.

During follow up some of the subjects' parents will develop MI. Lacking information about this may dilute our results because of subsequent misclassification of subjects.

Exclusions of participants who did not say if their parents had suffered a MI, may have introduced information bias, which seems unlikely: firstly, the baseline characteristics of responders and non-responders were almost the same. Even though some differences existed in HDL and alcohol in non-responders compared with responders to the question, it is not likely to have influenced the results as information bias requires both a different distribution of the risk factors and a different distribution of family history of MI. Secondly, subjects not answering the questions on family history of MI did not experience any excess MI incidence as compared with those without a family history. Thirdly, the incidence of MI did not differ when non-responders were included in different ways. Fourthly, the incidence of MI in subjects with a family history of MI was almost the same, independent of the definition of familial predisposition.

\section{Limitations related to the outcome}

These pertain to misclassification only. Our end point was defined as ICD-8 diagnosis number 410 , and included both fatal and nonfatal MI. It is possible that some MI cases have been coded under another diagnosis, for instance ICD-8 diagnosis numbers 411-4, 427 or 795-6 (sudden death), and hereby weakened the results somewhat. However, the register information is fairly accurate. In Denmark, all deceased residents are registered centrally and coded in a standardised manner by trained personnel using data from death certificates and any available necropsy reports. Studies of validity of the registers have shown that they include between 89 and $99 \%$ of clinically manifest MI. ${ }^{3640} 42$

Clinically unrecognised MIs were also not registered. This leads to an underestimation of the MI incidence, both in those subjects excluded from the analysis, and in the familial occurrence. It is well known that people with hypertension and diabetes mellitus have an increased risk of silent myocardial infarction. ${ }^{43}$ As both conditions are, at least in part, genetically determined, this may cause some familial aggregation of unrecognised MI.

\section{Conclusions}

Our findings provide compelling evidence that there is no consistent and significant interaction between a family history of MI and the cardiovascular risk factors in their influence on incidence of MI. We did, however, find a significant interaction on incidence of $\mathrm{MI}$ between family history of MI and HDL, but in men only; between family history of MI and alcohol intake, but in women only. These findings are in conflict with existing studies. We also found a significant interaction between family history of MI and inhalation in both women and men, but in opposite directions.

Because of the inconsistent findings we are reluctant to accept the contention that subjects with a family history of MI are more susceptible to the effect of other cardiovascular risk factors than subjects with no such history.

In this study, the RR of MI was increased in both women and men with a family history of MI as compared with subjects with no such history. Because of this excess risk, and because there is a clustering of several multiplicatively operating cardiovascular risk factors in subjects with a family history of MI, it may still be relevant to delinerate this group as an appropriate target group for screening and intervention for cardiovascular risk. However, our study demonstrated that a family history of MI does not reinforce the effect of the individual risk factors.

Funding: this study was supported by The Faculty of Health Sciences, University of Copenhagen; The Danish Medical Association Research Fund; The Danish Heart Foundation; and The Danish Medical Research Council (12-1661-1). The activities of the Danish Epidemiology Science Centre are
supported by a grant from the Danish National Research Founsuppor
dation.

Conflicts of interest: none.

1 Colditz GA, Stampfer MJ, Willett WC, et al. A prospective study of parental history of myocardial infarction and coronary heart disease in women. Am f Epidemiol 1986;123:48-58.

2 Hopkins PN, Williams RR, Kuida $\mathrm{H}$, et al. Family history as an independent risk factor for incident coronary artery disease in a high-risk cohort in Utah. Am $f$ Cardiol 1988;62:703-7.

3 Hunt SC, Williams RR, Barlow GK. A comparison of positive family history definitions for defining risk of future disease. F Chronic Dis 1986;39:809-21.

4 Rotimi C, Cooper R, Cao G, et al. Familial aggregation of cardiovascular diseases in African-American pedigrees. Genet Epidemiol 1994;11:397-407.

5 Schildkraut JM, Myers RH, Cupples LA, et al. Coronary risk associated with age and sex of parental heart disease in the Framingham Study. Am f Cardiol 1989;64:555-9.

6 Ciruzzi M, Schargrodsky H, Rozlosnik J, et al. Frequency of family history of acute myocardial infarction in patients with acute myocardial infarction. Argentine FRICAS (Factores de Riesgo Coronario en America del Sur) Investigators. Am 7 Cardiol 1997;80:122-7.

7 Hippe M, Vestbo J, Bjerg AM, et al. Cardiovascular risk factor profile in subjects with familial predisposition to myocardial infarction. $\mathcal{F}$ Epidemiol Community Health 1997; 51:266-71. 
8 Marenberg ME, Risch N, Berkman LF, et al. Genetic susceptibility to death from coronary heart disease in a study of twins. N Engl f Med 1994;330:1041-6.

9 Boomsma DI, Kempen HJM, Leuven JAG, et al. Genetic analysis of sex and generation differences in plasma lipid, lipoprotein, and apolipoprotein levels in adolescent twins and their parents. Genet Epidemiol 1996;13:49-60.

10 EARS. The distribution of fasting plasma lipid concentrations in the offspring of men with premature coronary hear disease in Europe. The EARS Study. Int f Epidemiol 1994; 23:472-81.

11 Masana L, Farinaro E, Henauw SD, et al. Blood pressure in young adults with and without a paternal histroy of premature coronary heart disease in Europe: the EARS Study. European Arteriosclerosis Study. F Hum Hypertens 1996; 10:207-13.

12 Sørensen TIA, Nielsen G, Andersen PK, et al. Genetic and environmental influences on premature death in adult environmental influences on premature

13 Boerwinkle E. A contemporary research paradigm for the genetic analysis of a common chronic disease. Ann Med 1996;28:451-7.

14 The Copenhagen Heart Study Group. The Copenhagen City Heart Study. Østerbroundersøgelsen. A book of tables with data from the first examination (1976-78) and a five year follow-up (1981-83). Appleyard M, ed. Scand $\mathcal{F}$ Soc Med 1989;170:1-160

15 Hagerup L, Eriksen M, Schroll M, et al. The Glostrup population studies, collection of epidemiologic tables. Scand F Soc Med 1981;suppl 20:5-112.

16 WHO MONICA Project Principal Investigators. The World Health Organization MONICA project (Monitoring Trends and Determinants in Cardiovascular Disease): A major international collaboration. $f$ Clin Epidemiol 1988; 41:105-14.

17 Hein HO, Suadicani P, Gyntelberg F. Ischaemic heart disease incidence by social class and form of smoking: the Copenhagen Male Study-17 years' follow-up. F Intern Med Copenhagen Male

18 Friedewald WT, Levy RI, Fredrickson DS. Estimation of the concentration of low-density lipoprotein cholesterol in plasma, without use of the

19 Clayton D, Hills M. Statistical models in epidemiology. Oxford: Oxford University Press, 1995:1-367

20 Feldman JJ, Makuc DM, Kleinman JC, et al. National trends in educational differentials in mortality. Am $\mathcal{F}$ Epidemio 1989;129:919-33.

21 Blair SN, Kampert JB, Kohl HW, III, et al. Influences of cardiorespiratory fitness and other precursors on cardiovascular disease and all-cause mortality in men and women. fAMA 1996;276:205-10.

22 Gaziano JM, Buring JE, Breslow JL, et al. Moderate alcohol intake, increased levels of high-density lipoprotein and its subfractions, and decreased risk of myocardial infarction. N Engl f Med 1993;329:1829-34.

23 Jensen G, Nyboe J, Appleyard M, et al. Risk factors for acute myocardial infarction in Copenhagen II: Smoking, alcohol myocardial infarction in Copenhagen II: Smoking, alcohol intake, physical activity, obesity, oral contraception, diabetes,

24 Simons LA, Friedlander Y, Simons J, et al. Familial aggregation of coronary heart disease: partial mediation by high density lipoproteins? Atherosclerosis 1988;69:139-44

25 Stampfer MJ, Krauss RM, Ma J, et al. A prospective study of triglyceride level, low-density lipoprotein particle diameter,
26 D'Avanzo B, Vecchia WL, Negri E. Height and the risk of acute myocardial infarction in italian women. Soc Sci Med 1994;38:193-6.

27 Myers RH, Kiely DK, Cupples A, et al. Parental history is an ndependent risk factor for coronary artery disease: The Framingham Study. Am Heart f 1990;120:963-9.

28 Friedlander Y. Sibling correlations of coronary heart disease risk factors in a sample of Israeli offspring with parental history of myocardial infarction. Atherosclerosis 1995;113: 259-71.

29 Roncaglioni MC, Santoro L, D'Avanzo B, et al. Role of family history in patients with myocardial infarction. An Italian case-control study. GISSI-EFRIM Investigators. Circulation 1992;85:2065-72.

30 Castro-Beiras A, Muniz J, Fernández-Fuertes I, et al. Family history as an independent risk factor for ischaemic heart disease in a low incidence area (Galicia, Spain). Eur Heart 7 1993;14:1445-50.

31 Khaw KT, Barrett Connor E. Family history of heart attack: modifiable risk factor? Circulation 1986;74:239-44.

32 Rossouw JE, Thompson ML, Jooste PL, et al. Relation of family history and reversible risk factors to coronary heart disease prevalence in an Afrikaner community. Arterioscler Thromb 1991;11:130-7.

33 Hopkins PN, Williams RR, Hunt SC. Magnified risks from cigarette smoking for coronary prone families in Utah. West f Med 1984;141:196-202.

34 Fuchs CS, Stampfer MJ, Colditz GA, et al. Alcohol consumption and mortality among women. $N$ Engl $7 \mathrm{Med}$ 1995;332:1245-50.

35 Madans JH, Reuben CA, Rothwell ST, et al. Differences in morbidity measures and risk factor identification using multiple data sources: the case of coronary heart disease. Stat Med 1995;14:643-53.

36 Nyboe J, Jensen G, Appleyard M, et al. Risk factors for acute myocardial infarction in Copenhagen. I: Hereditary, educational and socioeconomic factors. Eur Heart $\mathcal{f}$ 1989:10:910-16.

37 Greenlund KJ, Valdez R, Bao W, et al. Verification of parental history of coronary artery disease and associations with adult offspring risk factors in a community sample: the Bogalusa Heart Study. Am F Med Sci 1997;313:220-7.

38 De Backer G, Hulstaert F, De Munck K, et al. Serum lipids and apoproteins in students whose parents suffered prematurely from a myocardial infarction. Am Heart f 1986;112: 478-84.

39 Kee F, Tiret L, Robo JY, et al. Reliability of reported family history of myocardial infarction. BM7 1993;307:1528-30.

40 Mosbech J, Jфrgensen J, Madsen M, et al. The National Hospital Discharge Register. Evaluation of the data quality (Landspatientregisteret. Evaluering af datakvaliteten) [In Danish.] Ugeskr Lager 1995;157:3741-5.

41 Madsen M, Balling H, Eriksen LS. Validiteten af diagnosen akut myokardieinfarkt i to registre: Hjerteregistret sammenlignet med Landspatientregisteret. Ugeskr Leger 1990; 152:308-14.

42 Schroll M, Hansen B, Hansen U, et al. The incidence of myocardial infarction. Results from the Dan-Monica studies 1982-1984. (Myokardieinfarktincidensen i Danmark. Resultater fra Dan-Monica 1982-1984). [In Danish.] Uesultater fra Dan-Monica 1982

43 Niakan E, Harati Y, Rolak LA, et al. Silent myocardial infarction and diabetic cardiovascular autonomic neuropathy. Arch Intern Med 1986;146:2229-30. 